\title{
Teachers' Experiences and Perspectives of Implementing and Use of the Classroom Communication Resource (CCR) Intervention: Post Trial Reflections
}

\author{
Rizwana Mallick ( $\nabla$ rmallickst@gmail.com ) \\ University of Cape Town Faculty of Health Sciences https://orcid.org/0000-0002-7993-0512 \\ Harsha Kathard \\ university of cape town \\ Lehana Thabane \\ McMaster University \\ Mershen Pillay \\ University of Kwazulu-Natal
}

Research

Keywords: post-trial, interviews, reflections, qualitative, teacher experiences paradigms, speech-language therapy

Posted Date: June 9th, 2021

DOI: https://doi.org/10.21203/rs.3.rs-587769/v1

License: (c) (i) This work is licensed under a Creative Commons Attribution 4.0 International License.

Read Full License 


\section{Abstract}

Background: Post-trial interviews were conducted with teachers who administered the Classroom Communication Resource (CCR) intervention to grade 7 learners in a cluster Randomised Controlled Trial (RCT). The intervention addressed teasing and bullying using stuttering and communication as a case example. In alignment with the RCT, the study findings are presented relative to 1. Population, Intervention, Control, Outcome and Timeframe (PICOT);

Aim: To describe the teachers' experiences and reflections of implementing the CCR intervention and the future use of the intervention.

Objectives: To describe the teachers'

1. Suitability of the population at which the CCR was targeted;

2. intervention views including components of the CCR intervention (social story, role-play and discussion), resulting discussion and topics as well as modifications and recommendations;

3. control group researcher observations to contrast findings;

4. outcomes in terms of discussions, behaviour change and teacher observations;

5. time-frame suitability of the CCR.

Setting: The Western Cape Metropolitan Urban Area in South Africa.

Design: A qualitative exploratory study design was conducted. Teachers, in the intervention groups only, that is those who administered the CCR were interviewed using semi-structured interviews.

Participants: Eligible participants included grade 7 teachers from the lower and higher quintile schools who administered the CCR intervention to the grade 7 learners as part of the randomised controlled trial (RCT) study. The participants were not compensated financially for their time.

Sample size: A total of six teachers who administered the CCR intervention were interviewed.

Analysis: The interviews were transcribed verbatim and a thematic analysis was conducted. The data analysis procedure included: familiarisation with the data and generation of initial codes and categories which were clustered into themes.

Results: Overall, teachers found the CCR suitable for grade 7s (population) as a communication and teasing and bullying centered intervention that could be implemented in future with adaptations as a curriculum-imbedded intervention tool. It was recommended that in terms of timeframe, the CCR be implemented using ongoing and continuous activities within classroom lessons so solidify and consolidate key messages of the intervention. 
Discussion: This paper showed that extending the RCT was an invaluable and important step in contributing to the main trial findings. The additional layer of findings to the RCT showed that teacher collaboration is important in knowledge production. The paper also showed the need for a shift and the effects thereof on both methodology and paradigms (and vice versa) for knowledge production, clinically and for research.

Trial registration: Trails.gov (NCT03111524). Registered on 9 March 2017 prospectively.

\section{Background}

A Randomised Controlled Trial (RCT) was conducted to evaluate the effectiveness of the Classroom Communication Resource (CCR) intervention in schools in the Western Cape, South Africa (Mallick, Kathard, Borhan, Pillay, \& Thabane, 2018). The decision to conduct a RCT was taken upon the inundated literature that was consulted that prized this methodology (Botma, Greef, Malaudzi, \& Wright, 2016; Pocock, 2006) as gold standard (Heal, Groot, Sanders, \& Anders, 2017) due to its documented rigour (McCurtin \& Roddam, 2012; Pocock, 2006). The standing of a RCT within the research fraternity found this method ideal for stringent intervention testing (Pocock, 2006). The RCT was invaluable in providing information around the effectiveness of the CCR and subsequently guiding future research around the intervention itself, finding this method fitting.

However, the researcher felt great discomfort as there were many questions left unanswered. This discomfort stemmed from the fact that while the RCT used the best available methodology to test the $\mathrm{CCR}$, it did not provide information around practice and the end users - teachers - whose voices were missing in this intervention process. The teacher perspectives are therefore magnified in this paper and presented using the framework of the Population, Intervention, Control, Outcome and Timeframe (PICOT).

The translation of research into practice is paramount given that teachers will use the CCR. Despite teachers undertaking the role of interventionists, the RCT did not include their input beyond their participation in administration of the CCR. However, teachers' views were invited in the development stage of the CCR. It was therefore important to acquire teachers' input once again. The valued participation of teachers' post the RCT was seen as important because the value of a study also lies in exploring its applicability, context (Treweek \& Zwarenstein, 2009) and ability to make real-world meaning (Krauss, 2005). In RCTs, applicability is typically explored in terms of exploratory and pragmatic trials (Treweek \& Zwarenstein, 2009) whereas this study focused on post-trial reflections to add an important layer to the RCT findings. Consistent with the RCT, the PICOT framework is used to present the findings relative to the domains of Population, Intervention, Control, Outcomes and Timeframe.

\section{Methods And Design}

Primary aim: To describe the teachers' experiences and reflections of implementing the CCR intervention and the future use of the intervention. 
Objectives: To describe the teachers':

1. Suitability of the population the CCR targeted

2. Intervention perspectives views including components of the CCR intervention (social story, role-play and discussion), resulting discussion and topics as well as modifications and recommendations.

3. Control group researcher observations to contrast findings.

4. Outcomes in terms of discussions, behaviour change and teacher observations.

5. Time-frame suitability of the CCR

\section{Study design}

A qualitative exploratory study design was conducted once the stratified cluster RCT was complete. The schools were stratified into two quintile groups (lower vs higher) and then randomised to receiving the CCR intervention or usual practice with the school as the unit of randomisation. Teachers, in the intervention groups only, that is those who administered the CCR were interviewed.

\section{Participants}

\section{Inclusion and exclusion criteria}

Eligible participants included grade 7 teachers from the lower and higher quintile schools who administered the CCR intervention to the grade 7 learners as part of RCT study. Participants were not compensated financially for their time.

\section{Sample size}

A total of six grade 7 teachers who administered the CCR intervention were interviewed.

\section{Recruitment}

Recruitment took place as part of the RCT (Mallick, Kathard, Thabane, \& Pillay, 2018). In summary, this included obtaining a list of schools in the Western Cape Metro urban area from the Western Cape Education Department.

\section{Data collection method}

Semi-structured interviews were conducted. Interviews were conducted to allow teachers an opportunity to describe their perceptions and views of the CCR intervention administration tool as well as participating in school-based research. Semi-structured interviews were selected as it allowed for conversation using guided and structured questions (Botma et al., 2016). In doing so, the pre-determined questions were not close-ended so as not to hinder the feedback provided (c). Furthermore, it allowed the teachers to openly explore their experiences and perceptions by answering questions in a more open manner (Tetnowski \& Damico, 2001), while still addressing the objectives of this study. This was 
considered the most suitable method of obtaining the relevant information as it followed a guided approach while simultaneously allowing the researcher to follow the participants lead.

\section{Data collection instrument}

A semi-structured interview schedule was used, including a list of open-ended questions that aimed to address the objectives of the study. For example, as part of the objective related to the administrative process, the teachers were asked "can you tell me about your experience of administering the CCR intervention?". With regards to the components of the CCR intervention (social story, role-play and discussion) they were asked "what are your thoughts on the social story?" Under the objective of "Discussion, topics, learning and any effects such as behaviour change that emerged after the intervention" they were asked "What kinds of discussions emerged after you administered the CCR intervention?". As part of the objective related to the potential future use of the CCR intervention they will be asked "Would you use the CCR intervention as part of future learning? If yes, how and when would you make use of the CCR intervention in future?". They were asked "how would you modify the CCR intervention for future use?" as part of the objective related to "recommended modifications to the CCR intervention. The full interview schedule is attached (see appendix A).

\section{Research personnel}

The primary researcher, a Doctorate of Philosophy of Speech-Language Pathology student, conducted the interviews with teachers while a team of research assistants collected the 6 months post-intervention data. A research assistant reviewed the transcribed data, as described below.

\section{Procedure}

The RCT data collection procedure included four main phases, namely the preparatory, pre-intervention, intervention and post-intervention phases. The preparatory, pre-intervention and intervention phases were completed prior to this study. The post-intervention phase included 30-40 minute semi-structured interviews with intervention group teachers only. The interviews were conducted at each school in a quiet room while the research assistant conducted the final stages of the RCT data collection. Interviews were conducted at the same time as the final stages of the RCT due to time and logistical constraints as emphasised by all the schools. The interviews were recorded using an audio-recorder and the researchers made written,where necessary.

\section{Data collection, management and Analysis}

\section{Data management}

Following the interview process, the interviews were transcribed and analysed using thematic analysis to assist with generating themes. This data was stored electronically, using Microsoft documents. The data will be kept until December 2028, after which Prof Harsha Kathard, the research supervisor and principal investigator will be responsible for discarding the data. 


\section{Data analysis}

Thematic analysis of the transcribed interview data included: familiarisation of the data, coding, identifying, reviewing and defining and naming of themes. All information was compiled and presented within this paper using the PICOT framework. The phases were completed as follows:

Phase 1: Familiarisation with the data included the researcher transcribing the interviews after which a research assistant reviewed the transcribed data to ensure that no errors were made. Familiarisation of the data then occurred which included reading and re-reading the transcribed data in great depth (Braun \& Clarke, 2006). It was recommended that the researcher become immersed in the data to familiarise oneself in an active manner by searching for patterns and meaning within the data (Braun \& Clarke, 2006). The researcher made use of note-taking and began thinking about how to identify any ideas or themes for coding as they emerged from the familiarisation of the data (Braun \& Clarke, 2006).

Phase 2: Initial codes were generated as the researcher became more familiar with the data, during which notes were made of initial ideas for coding (Braun \& Clarke, 2006). Colour coding was used to highlight the objectives of this study. For example, "views on the administration of the CCR intervention" was highlighted in green while "components of the CCT intervention" was highlighted in blue, and so on. Postits and colour pens (and text online) were used (Braun \& Clarke, 2006) to assist with identifying themes.

Phase 3: identifying themes included searching for themes (Braun \& Clarke, 2006). This allowed the researcher to view the data in a broader sense than codes by re-focusing the thematic analysis (Braun \& Clarke, 2006). Thus, codes were analysed into themes, including different themes, sub-themes and or overarching themes (Braun \& Clarke, 2006). At this stage, the researcher made use of tables and thematic mind maps (Braun \& Clarke, 2006).

Phase 4: reviewing themes included the themes being generated in phase 3 were refined by looking at the level of the data extracts that were coded, i.e. did the extracts placed under each theme form any patterns (Braun \& Clarke, 2006)? Further refinement took place by examining the individual themes related to the data set in terms of validity, i.e. did the thematic map and themes adequately reflect the meaning and themes within the data as well as overall (Braun \& Clarke, 2006).

Phase 5: defining and naming of themes included themes being defined, refined and named (Braun \& Clarke, 2006). Again, the primary researcher considered how these themes fit within various extracts as well as the overall interview data (Braun \& Clarke, 2006). Objectives of this study were also used as a guideline for defining and naming the themes, where applicable as well as the PICOT framework of population, intervention, control, outcome and timeframe (Botma et al., 2016). It was important to note that the researchers remained open to what the data included so as to not limit the analysis of the interviews (Roulston, 2014).

Trial registration: The clinical trial is registered in Trails.gov and the number is NCT03111524. 
Funding: Funding was obtained from the National Research Foundation (NRF) Research and innovation support and advancement (RISA). The funding was granted to the Primary Researcher as a Doctoral bursary.

\section{Ethical Considerations}

In accordance to the Declaration of Helsinki (World Medical, 2013), autonomy, confidentiality, beneficence, non-maleficence and justice should be adhered to (Williams, 2008). These principles were upheld at all times to safeguard participants. The main RCT proposal has detailed how autonomy, confidentiality, beneficence, non-maleficence and justice will be upheld. In this study, autonomy was ensured by obtaining teacher consent again at this stage of the study, despite obtaining prior consent for the RCT. Teacher codes upheld confidentiality while there were no identified risks to participating in this study. Ethical approval was obtained from the University of Cape Town, Faculty of Health Sciences Research Ethics Committee (reference number: 442/2017).

\section{Results}

The results are presented in the PICOT framework whereby the population, intervention, control, outcome and timeframe, in accordance with the aims and objectives of this study. Thematic headings are also used within the PICOT presentation of findings. The quotes are coded where teachers are identified by HQ (higher quintile) or LQ (lower quintile)

\section{Population}

In this paper, the population of this study highlights the key role of the teachers and therefore echoes their voices.

\section{To administer the CCR to grade $7 s$, or not to administer to grade $7 s ?$}

In the RCT, the population was the grade 7 clusters of learners, as supported by previous studies in this project stream (Badroodien et al., 2011; De Freitas, Geben, Parusnath, Relleen, \& Van den Berg, 2012; De Grass et al., 2010; Filies, Hartley, Kaplan, \& Pettit, 2009; Frieslaar et al., 2013; Kathard et al., 2014; Mallick, Thabane, Borhan, \& Kathard, 2018; Walters, 2015). Teachers felt the CCR intervention was suited to grade 7 learners but also felt that it could be applied across grades in primary schools. Teachers also felt that each component -the story, role-play and discussion- were relatable for the grade 7s.

"It is a good starting point in grade 7"- THQ

"They could relate to the story because it was about young people and they would find themselves in a situation like this, you know, it's real. It's a real situation. It's not something that is fabricated, you know, it's something that is real. Possibly they could have been in a situation like that, where a child has been excluded from the group. It takes one person of that group just to say, "give that person a chance".". - THQ 
"The questions were clear, clearly put. It was something which the children could understand" - THQ.

\section{The younger the better for intervention}

Teachers reported that the CCR could be simplified for children as young as those in grade 1 as teasing and bullying is a major problem in all grades- starting from grade 1 .

"It can go across the board, it can go from grade 1 right to grade 7 and beyond even. It's a story which plays itself out all the time. It's a scenario which you find from grade 1"- THQ

"We would probably do is to take it to the isiXhosa teacher, translate it and do it for those kids probably from grade $4,5,6$, and 7 ." - THQ

"If you could maybe have it, the CCR, in different levels and then start at grade R" - THQ

"You can share it with anyone" - THQ

\section{Intervention}

Stuttering was the example used in the CCR as the case to illustrate discrimination based on communication. Stuttering as a specific communication difference/disorder foregrounded the general issue of communication and its importance in everyday meaning-making. Teachers valued the focus on communication as a topic and process.

"The story itself was you know, very interesting. The learners were shocked about the revelations from the story and then I think we had an opportunity to start talking about people who you know, were also having the same difficulty which was stuttering at school. They actually never thought that there would be help and support and that people would study towards stuttering and that it would then bring confidence and support to those learners who are withdrawn because of the stuttering challenges ahead. And in our community, all that we know we is that you will be laughed at if you're a stutterer and it is common"- TLQ.

"They said it was a real situation to find yourself in, not a make-believe thing so they found the story good. They also found the way that various characters were different from one another was interesting but yet they all work together in this band and came together as a group and how sometimes one, it takes one, this is the point, it takes one child just to make a difference quicker because this is what happens when there's a clique or a group, people are afraid to stand up for the underdog or for those who the others make fun of and tease. It takes courage for someone to stand up for a person like that because you stand to risk of being excluded from the group, being ostracised, or made fun of but in this case, it worked out well." - THQ

\section{Communication in everything}


Communication as a central theme was an aspect of the CCR that teachers particularly enjoyed. In fact, it was reported that this was favoured given that some students display difficulty expressing themselves. As such the CCR provided an opportunity for learners to practice their communication skills with their peers and teachers. Therefore, the CCR provided opportunity to create awareness of multiple dimensions of communication - over and above the issue of stuttering. A teacher, reporting on the intervention, found the CCR useful for practicing and developing communication skills.

"I especially liked the discussion part because that's where you are really drawing out their ideas, their thoughts, how do they feel, concepts of acceptance and diversity and many of them still struggle to express themselves. They might have a very valid point that they want to make but they don't know how to. Again, it's the communication so that is nice in the sense that it is even, the exercise itself lends itself towards that, helping them to communicate effectively and express yourself correctly." - THQ

"I can use that as a resource which will be very exciting. And then because of the repetition and the fact that they're exposed to that type of the thing in the intervention, the process is more solidified, in terms of what you are trying to achieve - you are trying to make the learner aware of problems in communication, how can we look at, um, ways to solve that etc." - THQ

"I liked how the learners interacted with the text and what they did from it and the way they responded to it. I liked that. And the entire discussion about communication. That worked well because remember we still did the mind maps, I think on the board. And I think they also did mind maps on their own pages about effective communication and different kinds of communication-verbal, non-verbal, gestures -that whole thing." - THQ

"Communication is something that a lot of children have difficulty with, you know? Even we as adults have difficulty. There self-confidence comes in, your ability, your language ability, command of the language, all those things come in, so this part of communication is very very important." - THQ

\section{Teasing and bullying is a real-world problem}

While teachers spoke about stuttering, they felt that the true focus was in fact teasing and bullying. In viewing and using the CCR as a teasing and bullying intervention, teachers said that they could contextualise the intervention according to the causes of teasing and bullying at their schools (e.g. money, weight etc.), i.e. knowing reasons for teasing and bullying provided insight into managing teasing and bullying.

"You know what, other kids have parents who are working, and they would have some money-probably for lunch to buy stuff- and all of that other kids would not have money, especially the younger ones don't have. It creates a problem and then you know that's where you find this bullying and fighting etc. because they are kids and they don't know how to handle this thing" - TLQ

"If we did stuttering, for example, one lesson we can use that same thing for bullying. You can use that same thing - the CCR-for self-esteem and also for helping one another, helping each other, that's what I 
say to my children also. We all here to, put on this planet, on this earth for a reason and we are there to help one another so you can use it for various objectives and skills."- THQ

Teachers reported value in relating the real-world problem of teasing and bullying when considering its long-term consequences such as suicide and cyber bullying (Blood \& Blood, 2007; Blood \& Blood, 2016; Brunstein Klomek et al., 2016; Cook \& Howell, 2014; Copeland, Wolke, Angold, \& Costello, 2013; Hawker \& Boulton, 2000; McAllister, 2015; McAllister, Kelman, \& Millard, 2015; Messenger, Packman, Onslow, Menzies, \& O'Brian, 2015; Vidal et al., 2007). The CCR was able to encourage discussion around feelings of being teased in addition to ways of being empathetic, supportive and accepting of diversity and difference. For example, teachers found that the CCR was a tool to mediate discussion around a positive view of diversity and difference.

"Teasing and bullying is so severe, and we already see it. What about the teenage suicide rate? What about the cyber bullying? We see that we are losing our kids to that type of thing. Why? Because we not interacting with each other. We are losing that as people and there is a bigger picture. It starts small but there's spill-offs. It's like it snowballs. So, if we get it right in the classroom then those learners will be out within their circles and then hopefully they will be able to apply some of the things"-." - THQ

"So, if we did stuttering, for example, one lesson we can use that same thing for bullying. You can use that same thing (CCR) for self-esteem. And also, for helping one another, helping each other, that's what I say to my children also." - THQ

Teachers report that the CCR was one method that could facilitate difficult discussions around teasing and bullying and so the intervention made it tangible for teachers and students. This was aligned with school-based interventions including anti-bullying posters and discussions. One school saw the need for teasing and bullying awareness to also cultivate and encouraging awareness of social justice and responsiveness, e.g. using Pro-Palestinian posters and marches.

"In school we are busy with on-going awareness program of bullying. I'm sure if you walk around you'll see the posters up about bullying" - THQ

"Then to just raise awareness of teasing and bullying because sometimes they are involved in something, but they don't know about all the other contextual issues surrounding that, and all the spill-offs, from a particular thing and I think that is important, especially if you try and drill that message at home with them that in terms of communication - be careful of what you say and how you say to someone because that then has consequences. Yes, it's very tricky now at their age. Even the way that they interact with each other, sometimes it's quite scary because you will find this slang and you'll find this street language and the gestures - gangster-related - that they would use, and it spills over into the classroom and you have to make them aware of that." - THQ

"We always talk about bullying and teasing and it's also on their classroom rules" - TLQ 
In addition to context in terms of causes of teasing and bullying differing in each school, teachers also spoke about contextual issues around teasing and bullying such as violence and gangsterism.

"They learn from the community and they bring it inside. The fighting, being territorial, fighting over very insignificant things. To a point where for me to understand them, I have to put myself in their shoes and then I always move from that premise to understand those little things that are actually the cause of the bullying and fighting. And the fact that there are times where socially, the economic disparities, the socioeconomic disparities in kids, those also bring this bullying attitude as well." - TLQ

\section{CCR alignment with school values}

Teachers also found the inclusion of personal qualities such as empathy and respect a key focus of the CCR to assist with promoting acceptance, diversity and difference. Personal qualities appeared to link between school values, curriculum and CCR values. For example, school values included respect, consideration and empathy, illustrated by classroom posters, classroom rules, code of conduct and antibulling posters. The CCR was viewed as a support to these values and personal qualities as opposed to a rigid intervention consisting of a list of dos and don'ts.

"The story would be a good starting point to bring certain values home to the children. Not only one but more- respect, respect for self, for others, acknowledging that everybody's different, everybody's not the same perseverance. I think there was a bit of perseverance in there. You could use this for so many values. The story can be used to introduce a lot, of perseverance as I said also, honesty, integrity, how to overcome obstacles, overcome what you see, or the child sees [as] a disability so there's various things for which the story can be used for." - THQ

"It's something that we shouldn't neglect, this this type of thing forms part of life skills."- THQ

"I strive for this every day, well not every day, most days I would bring up, or something comes up and I use that as a starting point to bring across whatever lesson. So, for example, today I was telling them about grit. I watched a ted $x$ talked and I asked them those of you who please have computers at home, ask your parents to go onto ted $x$ and you can see it on YouTube and they had a presentation and then I gave the whole "what is a presentation" so we bring vocabulary into that and we bring language in to that. So, what is a presentation, we have various people coming on there, they are motivational speakers and I told them about this one that I saw recently where this one woman says she was a teacher. She became a psychologist and she and her research team wanted to know what is it that makes some people successful and others not. What is it? Is it intelligence? Is it money? Is it looks? Is it? And they came to the conclusion that it's neither of those. Not your IQ, not your looks, not your background, not your money not your status, anything like that but sheer grit. Its grit that gets you through life.

Perseverance and I wrote it big on the board "grit". Let's look at the word "grit" and we said how and what grit means. Perseverance. Never giving up. Never thinking that I can't do it. All that. Almost like making a mind map so those are the things, I never plan those things. I think years of experience, of being a teacher, it comes naturally to me so this type of thing - value-based talks -is something which I incorporate in my 
classroom many a times. It could be anything. It could be about truthfulness, about integrity. All those things. Something happens (at school) and I take it as a starting point." - THQ

"What I liked is the message that we must not judge, like the phrase that you use in English that says, "don't judge a book by its cover"." - TLQ

\section{Sustained intervention}

Teachers felt that the CCR's repetition in the activity itself was favourable. However, they felt that the CCR, overall, was not as effective as a single-dose intervention and instead considered its use within a curriculum-based and imbedded approach, such as in the curriculum assessment policy referred to as CAPS.

"As a lesson, I would say that the way you set the CCR out, worked well because of the repetition. Because there was the story that was told and then the learners could then at that point, when we brought in the role-play- they knew where and what the story was about. They had an idea about the character that they had to assume the role of so, I think that the learners enjoyed the role-play. That repetition also worked well because it touched on the theme of stuttering, so the learners could then relate completely once the discussion started." - THQ

"Now you see because changing attitudes is a long-term type of activity, you have to gauge how to do this. Now for us, you came in, you did it (administered the questionnaire) and it was just out of nowhere that you come back with another questionnaire so there's no continuity and that is sort of what you are looking for. So, if I am doing this theme over a week, I think it would be a bit better for the learners."- THQ

"I think that it would be great to have more themes like this in the particular in the CAPS, that we actually running with the learners at school, making them more aware of real issues, things that they can really relate to. It would be great to have that type of stories." - THQ

\section{Integrating the CCR into the curriculum}

Examples were provided in terms of how the CCR could be used in the curriculum in school subjects such as Life Orientation and English. In addition to teachers reporting that it would be good to use the CCR as a curriculum-based intervention, it was reported that it could be used flexibly as long as learning was solidified using classroom methodologies. Classroom methodologies included themes and ongoing discussions which was a gap within CCR.

"I would actually use it with the Life orientation lessons" - Teacher who administered the CCR at a higher quintile school.

"The Life Orientation teacher can also use this because I can see that it has an inclination towards life orientation as well so it's quite a rich document. - TLQ 
"The nice thing about this, this could work across curriculum because it would fit in beautifully with an English lesson and it would fit in beautifully with a Life Orientation lesson as well, and probably even lend itself to some other kind of subjects where that type of discussion comes up. So, I think for now strongly across English and Life Orientation and that there is a nice tie-in with that, with[in] those two subjects."THQ

"For instance, if I need to cover language aspects, I will then build it into the story that I'm using or in the comprehension task, so I will then take that as my theme and then set a comprehension on it - whereas you just had a discussion. I will do a discussion activity that will be part of my listening and speaking tasks. Then I have to have a comprehension component and a language component, so I'll base my language lesson on the sentences and things you use. For instance, I want to teach compound and complex sentences and your passage in the story lends itself to a lot of that examples then I will use of those sentences to build into mine."- THQ

"It's the balance language approach - what we call the BLA. So that entire CCR, I will then base all my lessons on so, my discussion will be my oral. I can maybe even have an oral, which will be the role-play and then I can even have a writing activity-an essay on bullying or whatever else, so for the child who stuttered or whatever-lead them into a narrative." - THQ

"There's a lot of stuff, and language that I can cover that I will definitely try and solicit out of this. Even during revision when I go to certain aspects of grammar, I can use this. One other thing that we can do is the direct and indirect speech on the role play." - TLQ

"I would definitely break it up into chunks you know as specific areas to what I would be teaching at the time, for example direct and indirect speech." - TLQ

"I would use it in life skills where the children have to perform like in performing arts and then in that you could incorporate language because you can have speech bubbles and we have direct and indirect speech also) and you can work around that and just be creative." - THQ

\section{Control}

No interviews were held with teachers in the control group. However, teachers in control groups displayed an eagerness to receive the CCR as well as training on how to use the intervention. Control group teachers expressed interest in the CCR and inquired if they could share it with colleagues.

\section{Outcome}

\section{What did the teachers see?}

The RCT focused on attitudinal changes, under the premise that attitude is the precursor to behaviour change. This means that the RCT did not measure behaviour change itself. The findings of the RCT was 
that there was no statistically significant change in attitudes. However, teachers reported behaviour had changed and were reported based on observations of their classrooms.

\section{"The laughter stopped"}

Initially there was laughter when the students viewed the video of the CWS which continued once the CCR was administered. The laughter did however subside over time and the grade $7 \mathrm{~s}$ became interested in the CCR and its message. The initial laughter appeared to indicate discomfort.

"They became more interested. Initially it was a bit of giggling, but they settled down after that." - THQ

"They were laughing when there were examples about stuttering" - TLQ

"I found that most of them at first- the very first time that you were here - they thought that it was like a joke but the CCR activities actually made them aware that stuttering, communication, teasing and bullying is actually a real problem." - THQ

"It kind of opened their minds to what it feels like to stutter or be made fun of and that it's not just a laughing matter." - THQ

\section{"They identified people who stutter"}

Additionally, students came to their teachers with questions and reflections such as reports of people they knew who stuttered.

"They actually did speak about it again" - THQ

"I think maybe one or two of the learners came up to me afterwards just to make a comment, maybe about someone that they know in the family, that type of thing and just speak around that and maybe just awareness around that" - THQ

\section{A peek in interest}

The students engaged with, enjoyed and identified with the story.

"The kids were just reading a story, like any other story and it captivated and captured them, like any other good story would do and to have the kids involved, doing it themselves, not exactly knowing where the story was actually leading them. You know, when I looked at their faces, when things were beginning to gel it was quite interesting you know. They enjoyed it very much." - TLQ

The students particularly became interested when the role-play began, and they could engage in the activities of the CCR more actively (than listening to a story).

"Firstly, they were very eager. I had lots of hands when I was choosing the characters. There weren't shy. There were many learners that wanted to participate in this. Once we chose the different characters, that 
was also when the class settled down to listen to the various interactions with the characters" - THQ

\section{"They questioned their peers, and reflected"}

Teachers later noted that students who had the CCR administered in their classrooms had begun questioning peers for laughing at others. Teachers also noted that students were more open to interacting with peers who would be considered "different".

"You know they sat down and gave it some thought because they were actually like "really mam?" like "I didn't even think about it like that. I just found it funny all the time". Things like that where they actually now sat down and thought about [it]." - THQ

"I will tell you [that] there is one learner, whom they know in grade 6, in one of the classes I teach, is also a learner who stutters. I could see the way [that] they were relating to him, it was different. They were people who were informed, unlike before" - TLQ

"They were very impatient, and they would laugh at him. And even this boy himself, he developed a defense mechanism and he knew exactly how to deal with them and what he will do in response to them. But things have changed. They're very patient with him and they listen more when they speak to him. They understand that he has this challenge but it's something that can also be helped." - TLQ

"And you can see that there is a better effort of those kids towards supporting one another." - TLQ

"I think they changed because they were taught that like we are all the same and we must not treat other learners differently although they might have some problems, but we must treat them the same because we are all human beings with individual differences" - TLQ

\section{Timeframe}

\section{The good, the bad and the disjointed}

The dosage of the CCR was a concern of the teachers. While they reported that 6 months was considered an adequate timeframe, they raised concerns around the CCR being a single-dosage intervention. Teachers felt that there was need for continuous learning and engagement to ensure that the CCR learning and research was not disjointed from the rest of the learning happening in the classroom. Furthermore, teachers felt that there was a need to include the CCR as part of learning using sequential classroom lessons and themes. As such, teachers reported that more thought into the pacing and spacing of activities was required if the CCR was to be effective. The need for both students and teachers to make sense of the CCR within an ongoing time frame and learning was noted. This would also address the concern that the CCR was too long for a once-off classroom lesson.

"I would actually break it up because I think in chunks it would actually make more sense than completing everything all in one go. You could actually discuss part of it as you go along. Maybe the first lesson - "what it is", "why" and so on. You can get some questions and see what they have to say and 
maybe after that, in the next lesson, we do the role-play and then we can discuss the role-play. And what other people's opinions are and not just take the opinions of the story and "dump" it onto them because some of them have their own things to say." - THQ

"A repeated learning, or not even necessarily repeated but there is a block. Do you know what I'm saying? I'm focusing on that as a theme so that I can bring my children back to- "remember when we focused on the theme of communication?" - THQ

"I would break it up. Firstly, I would read the story and tell them to think about it and just to take it in and think about it. Go home and think about it, talk to your parents about it, say what you learnt about it. I would take it not all in one go." - THQ

\section{Discussion}

Through working with teachers, this study shows the importance of collaboration and that more collaborative partnerships are required. In fact, this study could be viewed as incomplete without the teacher collaboration. Teacher agency and the role of the teacher in interventions (Moonsamy \& Kathard, 2015) such as the CCR is important, and is highlighted in this paper, because the CCR is a teacher driven intervention. While SLT and teachers are intervention partners, the teacher administers the CCR and is thus an integral part to the intervention. It is also important to understand that the CCR may appeal to some teachers and this would influence how it is administered. Collaboration was important as it allowed the issues that matter to teachers, be highlighted in this paper. While teachers have called for intervention (Abrahams, Harty, St.Louis, Thabane, \& Kathard, 2016) making the CCR and its effectiveness important this paper shows that there is more to interventions than effectiveness. In doing so, this paper helped us to consider how to make this research more real and applicable by illustrating the importance of the translation of research into practice by helping us rethink the CCR application from a teacher perspective.

It is essential that SLTs understand their collaboration with teachers beyond their requests for assistance with managing communication in classrooms (Abrahams et al., 2016) and shift towards viewing teachers as valuable communication partners. The CCR is therefore a tool that teachers could potentially use - and now with the findings of this study the researchers can adapt the CCR accordingly.

Teachers play a pivotal role in students' lives, they shape and mould their learning and spend large amounts of time with students. According to (Hartas, 2004) teachers viewed teamwork as an important aspect of collaboration amongst teachers and SLTs and that complimentary roles during collaboration would facilitate working towards the common goal of student development and learning (Hartas, 2004). While (Miller, 2002) reported several barriers such as the disconnect between teachers and SLTs, it was reported that teachers and SLTs both saw value in collaborating with one another. Furthermore, it is stated while collaboration gains traction, it becomes important that research-based evidence is generated to underpin how collaborative practices are put in place (Hartas, 2004). 
This paper additionally challenges the use of an expert model of practice when collaborating with teachers. The RCT drew on the expert model with teachers being trained to use the CCR. However, the relational issues and power dynamics of the RCT illustrated that there is value in moving away from an expert model and towards more collaborative practices. This paper illustrates the importance of breaking away from an expert model allows for SLTs and researchers to hear what teachers feel and think. In doing so, our practices and interactions with teachers are more likely to change, also aiming to work towards a decolonisation process of teacher and SLT collaboration.

Implications: Based on the feedback from teachers, the true focus of the CCR was on communication even though the case of stuttering was used as well as teasing and bullying. The teachers enjoyed multimodal communication aspects of the CCR and how the tool facilitated communication in the classroom. Teachers were also viewed as interventionists and participants in this study, showing that further collaboration is valuable and needed.

\section{References}

1. Abrahams, K., Harty, M., St. Louis, K. O., Thabane, L., \& Kathard, H. (2016). Primary school teachers' opinions and attitudes towards stuttering in two South African urban education districts. South African Journal of Communication Disorders, 63, 1-10.

2. Botma, Y., Greef, M., Malaudzi, F. M., \& Wright, S. C. D. (2016). Research in Health Sciences (6 ed.). Cape Town: Pearson South Africa.

3. Braun, V., \& Clarke, V. (2006). Using thematic analysis in psychology. Qualitative Research in Psychology, 3(2), 77-101. doi:10.1191/1478088706qp063oa

4. Hartas, D. (2004). Teacher and speech-language therapist collaboration: being equal and achieving a common goal? Child Language Teaching and Therapy, 20(1), 33-54.

doi:10.1191/0265659004ct262oa

5. Heal, J., Groot, B., Sanders, M., \& Anders, J. (2017). Running RCTs with complex interventions. Retrieved from https://www.behaviouralinsights.co.uk/trial-design/running-rcts-with-complexinterventions/

6. Hobbs, A., Lewis, J., Kamedien, L., Sindi, A., Stijkel, K., \& Stoto, S. (2016). Teachers' Perceptions and Experiences of Stuttering in Lower Quintile Schools in the Western Cape. (BSc Speech-Language Pathology), University of Cape Town, South Africa, Unpublished undergraduate thesis.

7. Mallick, R., Kathard, H., Thabane, L., \& Pillay, M. (2018). The Classroom Communication Resource (CCR) intervention to change peer's attitudes towards children who stutter (CWS): study protocol for a randomised controlled trial. Trials, 19(1), 43. doi:10.1186/s13063-017-2365-x

8. McCurtin, A., \& Roddam, H. (2012). Evidence-based practice: SLTs under siege or opportunity for growth? The use and nature of research evidence in the profession. Int $J$ Lang Commun Disord, 47(1), 11-26. doi:10.1111/j.1460-6984.2011.00074.x 
9. Miller, C. (2002). Learning from each other: practitioners in school-based support for children with language and communication needs. Support for Learning, 17(4), 187-192.

10. Moonsamy, S., \& Kathard, H. (2015). Speech-language therapy in a school context: principles and practice (1 ed. Vol. 1). Pretoria, South Africa: Van Schaik.

11. Roulston, K. (2014). Analysing interviews: The SAGE Handbook of Qualitative Data Analysis. London: Sage publications Ltd.

12. Treweek, S., \& Zwarenstein, M. (2009). Making trials matter: pragmatic and explanatory trials and the problem of applicability. Trials, 10(1), 37. doi:10.1186/1745-6215-10-37

13. Williams, J. R. (2008). The Declaration of Helsinki and public health. Bulletin of the World Health Organization, 86, 650-651.

14. World Medical, A. (2013). World medical association declaration of Helsinki: Ethical principles for medical research involving human subjects. JAMA, 310(20), 2191-2194.

doi:10.1001/jama.2013.281053

\section{Supplementary Files}

This is a list of supplementary files associated with this preprint. Click to download.

- equatornetworkchecklistreferencedformystudy.pdf 